\title{
AVALIAÇÃO DA POROSIDADE E PLACA FÉRRICA DE RAÍZES DE ARROZ CULTIVADO EM HIPOXIA ${ }^{(1)}$
}

\author{
Marquel Jonas Holzschuh ${ }^{(2)}$, Humberto Bohnen ${ }^{(3)}$ Ibanor Anghinoni $^{(4)}$
}

\begin{abstract}
RESUMO
A alta difusividade do oxigênio em diversos materiais dificulta a criação e, ou, manutenção de um ambiente livre de $\mathrm{O}_{2}$. As técnicas utilizadas são pouco eficientes na exclusão do $\mathrm{O}_{2} \mathrm{e}$, portanto, não expressam a condição do solo alagado. Os objetivos deste trabalho foram desenvolver um método para obtenção de raízes em condição de hipoxia e avaliar a placa férrica e a formação de aerênquima no arroz. Foi criada uma condição de hipoxia semelhante à do solo alagado em tanques de $50 \mathrm{~L}$, explorando a capacidade de difusão do $\mathrm{O}_{2}$ por meio do vinil em contato com solo reduzido. Cada tanque preenchido com solo (Gleissolo háplico) recebeu cinco sacos de vinil e foi mantido alagado. Plantas dos genótipos IRGA 423 e IRGA 424 previamente cultivadas em campo foram coletadas, tendo as raízes cortadas junto ao colo, lavadas e um terço da lâmina foliar removido. Cada saco de vinil recebeu 12 plantas de cada genótipo e solução nutritiva. Após sete dias, as novas raízes adventícias formadas foram utilizadas na determinação da porosidade e a da placa férrica em segmentos de 0-2, 2-4 e 4-6 cm a partir da ponta da raiz. As raízes foram colocadas em contato com a solução de um solo em processo de redução por $4 \mathrm{~h}$ e a placa férrica determinada após a extração do $\mathrm{Fe} \operatorname{com} \mathrm{HCl} 0,5 \mathrm{~mol} \mathrm{~L}^{-1}$. A porosidade foi determinada pela aplicação de ciclos de vácuo, com auxílio de seringas. A diferença de peso antes e depois do tratamento com vácuo e entrada de água foi assumida como sendo a estimativa da magnitude do aerênquima ao longo da raiz. A eficácia do método foi testada com a produção de raízes adventícias em saco de vinil com aeração e hipoxia. A porosidade nas raízes foi maior em ambiente hipóxico, comparado à aeração. A porosidade foi maior na proximidade da base da planta e, à medida que a porosidade aumentou, houve aumento do conteúdo de $\mathrm{Fe}$ na superfície das raízes, indicando que a placa férrica pode servir como estimativa da formação de aerênquima no arroz. O método de obtenção de raízes foi eficiente em promover a eliminação de $\mathrm{O}_{2}$ do saco de vinil para estudar a formação do aerênquima.
\end{abstract}

Termos de indexação: anaerobiose, Oryza sativa L., aerênquima.

(1) Trabalho financiado pelo Instituto Rio-Grandense do Arroz - IRGA. Recebido para publicação em agosto de 2009 e aprovado em agosto de 2010.

(2) Doutorando do Programa de Pós-Graduação em Ciência do Solo, Universidade Federal do Rio Grande do Sul - UFRGS. Av. Bento Gonçalves 9500, CEP 91501-970 Porto Alegre (RS). Bolsista CAPES. E-mail: marquelrs@yahoo.com.br

(3) Consultor Técnico do Instituto Rio-Grandense do Arroz - IRGA. Av. Bonifácio Carvalho Bernardes 1494, CEP 94930-030 Cachoeirinha (RS). E-mail: humbertobohnen@uol.com.br

(4) Professor do Departamento de Solos, UFRGS. Bolsista CNPq. E-mail: ibanghi@ufrgs.br 


\title{
SUMMARY: EVALUATION OF POROSITY AND IRON PLAQUE ON RICE ROOTS GROWN UNDER HYPOXIA
}

\begin{abstract}
The high oxygen diffusion in different materials makes the establishment and maintenance of oxygen-free environments difficult. The techniques used to obtain oxygen-free environments are little efficient and not representative of flooded soil conditions. The purpose of this study was to develop a method for obtaining roots in a hypoxic environment to evaluate iron plaque and aerenchyma formation in rice plants. A hypoxic condition similar to that of flooded soils was created in $50 \mathrm{~L}$ tanks, based on the oxygen diffusion capacity through vinyl plastic in contact with flooded soil. Each tank was filled with soil (Gley soil), five vinyl bags and then flooded. Rice plants of the genotypes IRGA 423 and IRGA 424 grown in the field were collected, the roots cut at the stem, washed and 1/3 of the leaves removed. Each bag was filled with 12 plants of each genotype and nutrient solution. After seven days, the new adventitious roots were used to determine the iron plaque and aerenchyma formation in the segments 0-2, 2-4 and 4$6 \mathrm{~cm}$ from the root tips. The roots were exposed the solution of a flooded soil for 4 hours. The iron plaque was determined in the root segments after iron extraction with $\mathrm{HCl} 0.5 \mathrm{~mol} \mathrm{~L} \mathrm{~L}^{-1}$. Porosity was determined in vacuum cycles applied with a syringe. The weight difference before and after vacuum treatment and water entrance was assumed as estimate of the magnitude of the aerenchyma of the roots. The method was tested with the production of new adventitious roots in vinyl bags under aerated and hypoxic conditions. Root porosity was higher in the hypoxic than in the aerated environment. Porosity was higher near plant base and as porosity increased, iron increased near the root surface, indicating the iron plaque as a parameter to estimate aerenchyma formation in rice roots. The tested root-growth method was efficient in eliminating $\mathrm{O}_{2}$ from the vinyl bags to study aerenchyma formation.
\end{abstract}

Index terms: anaerobiosis, Oryza sativa L., aerenchyma.

\section{INTRODUÇÃO}

Nos solos cultivados sob alagamento, a baixa taxa de difusão do $\mathrm{O}_{2}$ na lâmina de água determina a formação de camadas distintas quanto ao regime de $\mathrm{O}_{2}$ no solo. Há uma camada superficial oxidada de alguns milímetros e, abaixo desta, é formado um ambiente com pouco ou nenhum $\mathrm{O}_{2}$ (Ponnamperuma, 1972). Para manter o crescimento em ambiente sem $\mathrm{O}_{2}$, as plantas de arroz sofreram adaptações estruturais na parte aérea e nas raízes, que lhes permitem transportar o $\mathrm{O}_{2}$ necessário para promover a respiração celular nos pontos de crescimento (Jackson \& Armstrong, 1999). A redução na concentração de $\mathrm{O}_{2}$ no solo com o alagamento (hipoxia) desencadeia uma série de processos bioquímicos na planta, os quais podem estimular a formação de aerênquima. Este pode ser classificado em esquizógeno ou lisígeno, de acordo com o processo de formação. $\mathrm{O}$ aerênquima esquizógeno ou constitutivo resulta da separação das células e dos espaços intercelulares, devido ao arranjo diferencial das células que compõem os tecidos, e pode ser encontrado mesmo em plantas bem supridas com $\mathrm{O}_{2}$ (Jeffree et al., 1986; Evans, 2003). Por outro lado, o aerênquima lisígeno é formado a partir da morte das células em resposta às condições adversas impostas pelo ambiente, principalmente a falta de $\mathrm{O}_{2}$ (Jackson \& Armstrong, 1999; Colmer, 2003; Evans, 2003). A sua formação ocorre primeiramente nas raízes, sobretudo nas adventícias, quando as células dos pontos de crescimento percebem a presença de algum fator limitante ao metabolismo e se estendem para a base da planta e parte aérea (Thomson et al., 1990). O aerênquima lisígeno é o tipo de formação predominante nos tecidos do arroz (Justin \& Armstrong, 1991) e pode variar de $5 \%$ na ponta até $45 \%$ em regiões maduras da raiz (Luxmoore et al., 1970; Armstrong, 1971).

$\mathrm{O}$ transporte do $\mathrm{O}_{2}$ através do aerênquima ocorre em resposta a um fluxo difusivo da atmosfera, passando pela parte aérea até chegar à raiz (Groot et al., 2005), devido à demanda criada pela atividade respiratória da raiz e pela perda radial de $\mathrm{O}_{2}$. Fatores como temperatura do solo (Hosono \& Nouchi, 1997) e condições redox (Kludze et al., 1993) influenciam na atividade respiratória dos organismos do solo, aumentando o consumo de $\mathrm{O}_{2}$ na rizosfera. A intensidade do transporte interno de gases é influenciada por fatores intrínsecos da planta, determinados por sua carga genética, sugerindo que haja diferenças entre espécies e até mesmo entre cultivares, como é o caso do arroz (Aulakh et al., 2000). Plantas que possuem maior capacidade de formar aerênquima teoricamente transportam mais $\mathrm{O}_{2}$ para a ponta das raízes, podendo favorecer o seu crescimento e, consequentemente, promover maior aprofundamento do sistema radicular, o que pode ser 
desejável em vista do volume de solo explorado na busca por nutrientes. Entretanto, o $\mathrm{O}_{2}$ transportado até a raiz pode, em parte, se difundir para o solo em virtude do gradiente de $\mathrm{O}_{2}$ criado entre o solo e o interior da raiz. A intensidade com que ocorre essa perda é determinada por características da raiz, como o espessamento da parede celular, região da raiz e volume de aerênquima (Clark \& Harris, 1981; Colmer, 2003; Evans, 2003). O espessamento secundário das paredes celulares atua como uma barreira que reduz a liberação de $\mathrm{O}_{2}$ e varia ao longo da raiz, à medida que esta se torna mais velha, sendo mais permeável nas zonas de crescimento (Armstrong, 1979). Devido à variação no volume de aerênquima entre cultivares, a quantidade de $\mathrm{O}_{2}$ liberado pelas raízes do arroz pode ser diferente e influenciar o desenvolvimento de microrganismos aeróbios junto à rizosfera (Colmer, 2003; Evans, 2003). Isso pode alterar a intensidade das reações químicas e biológicas e, consequentemente, a disponibilidade de alguns nutrientes importantes para as plantas, como o N (Ponnamperuma, 1972).

Durante os processos de redução química que ocorrem no solo, o Fe oxidado $\left(\mathrm{Fe}^{3+}\right)$ passa para a forma reduzida $\left(\mathrm{Fe}^{2+}\right)$, aumentando a sua solubilidade e, por conseguinte, a sua disponibilidade para a planta (Ponnamperuma, 1972). Por outro lado, a liberação de $\mathrm{O}_{2}$ das raízes para a rizosfera possibilita a oxidação do $\mathrm{Fe}$, gerando novamente a transformação para a forma $\mathrm{Fe}^{3+}$. Essa oxidação resulta na acumulação de Fe na superfície e nas células da epiderme da raiz (Tanaka, A. \& Navasero, 1966) na forma de oxihidróxidos de Fe pouco cristalinizados, comumente denominada de placa férrica (Chen et al., 2006). A magnitude da formação da placa férrica tem sido relacionada, em alguns casos, com a tolerância ao excesso de $\mathrm{Fe}\left(\mathrm{Fe}^{2+}\right)$ em solos alagados, no sentido de reduzir a sua entrada na planta (Tanaka, A. \& Navasero, 1966; Chen et al., 1980). Por outro lado, a acumulação das formas oxidadas de Fe também tem sido apontada como uma barreira para a absorção normal de outros nutrientes essenciais (Chen et al., 1980). De acordo com estes autores, a formação da placa férrica é variável entre cultivares de arroz e até mesmo entre estádios de desenvolvimento e a determinação da quantidade de $\mathrm{Fe}$ oxidado poderia servir como atributo para diferenciar cultivares quanto à sua capacidade de transportar e liberar $\mathrm{O}_{2}$ para a rizosfera.

A facilidade do $\mathrm{O}_{2}$ em se difundir através de materiais orgânicos e água dificulta a criação e, ou, manutenção de um ambiente livre de $\mathrm{O}_{2}$ molecular quando se trabalha em solução nutritiva com arroz. Algumas técnicas que têm sido utilizadas para esses estudos, como cultivo em meios contendo ágar e em recipientes permeáveis ao $\mathrm{O}_{2}$, principalmente os plásticos, exclusão do $\mathrm{O}_{2} \operatorname{com~} \mathrm{N}_{2}$, sais inorgânicos redutores, entre outros, não têm sido muito eficientes na exclusão do $\mathrm{O}_{2}$ do ambiente radicular, levando a conclusões que nem sempre expressam a situação de uma planta de arroz no solo alagado, sobretudo os estudos realizados em meios artificiais. Assim, com os objetivos de obter raízes para estudo da placa férrica e estimar a magnitude do aerênquima, foi desenvolvido um método original para a cultura do arroz, sem o contato direto com o solo alagado, mas que proporcione uma condição de hipoxia semelhante à das condições naturais.

\section{MATERIAL E MÉTODOS}

O experimento foi conduzido na Estação Experimental do Arroz (EEA) do Instituto Rio-Grandense do Arroz (IRGA) (Cachoeirinha-RS), no período de novembro de 2008 a fevereiro de 2009.

\section{Obtenção de raízes de arroz em ambiente de hipoxia}

O trabalho foi conduzido em casa de vegetação, com temperaturas variando entre 20 e $30{ }^{\circ} \mathrm{C}$. A condição de hipoxia foi obtida explorando-se a capacidade de difusão do $\mathrm{O}_{2}$ por meio do material plástico de vinil em contato externo com solo em processo de redução. Para isso, foram produzidos sacos de vinil com espessura de $0,1 \mathrm{~mm}$ e dimensões de 30 x $40 \mathrm{~cm}$. As Unidades Experimentais (UEs) foram compostas por tanques com capacidade de $50 \mathrm{~L}$. Cada UE recebeu cinco sacos de vinil, os quais foram colocados sobre uma camada de solo de $5,0 \mathrm{~cm}$ no fundo da caixa e afastados 10,0 cm entre si. Em cada saco foi colocado um espaçador interno (condutor elétrico de $10 \mathrm{~mm}$ de diâmetro), com o objetivo de manter um espaço adequado para que as raízes crescessem sem impedimento físico. A caixa foi preenchida com solo (Gleissolo Háplico) (Streck, 2008), deixando a abertura do saco a 10,0 cm acima da superfície (Figura 1). Cada saco recebeu $150 \mathrm{~mL}$ de solução nutritiva (Silva $\&$ Bohnen, 2001). O solo foi alagado e mantido com uma lâmina de água de $5,0 \mathrm{~cm}$.

Plantas dos genótipos IRGA 423 e IRGA 424 cultivadas no campo até o início do florescimento foram retiradas inteiras do solo e levadas ao laboratório, onde perfilhos uniformes e vigorosos foram separados, tendo todas as raízes cortadas junto ao colo da planta. As plantas foram cuidadosamente lavadas, para evitar a contaminação com solo no cultivo de raízes. A fim de reduzir a taxa de transpiração, um terço da lâmina foliar foi removido. Essas plantas foram alocadas nos sacos de vinil, de forma que o colo delas ficasse posicionado na altura da superfície do solo. Cada saco recebeu 12 plantas de cada genótipo. Após um período de sete dias, com novas raízes adventícias formadas, as plantas foram retiradas dos sacos e levadas imediatamente para o laboratório (Figura 2). A solução nutritiva foi regularmente reposta nos sacos, à medida que a transpiração reduzia o volume. Análises de monitoramento do $\mathrm{O}_{2}$ dissolvido nos sacos durante o período de formação de raízes indicaram concentração inferior a $0,1 \mathrm{mg} \mathrm{L}^{-1}$ junto ao colo das 


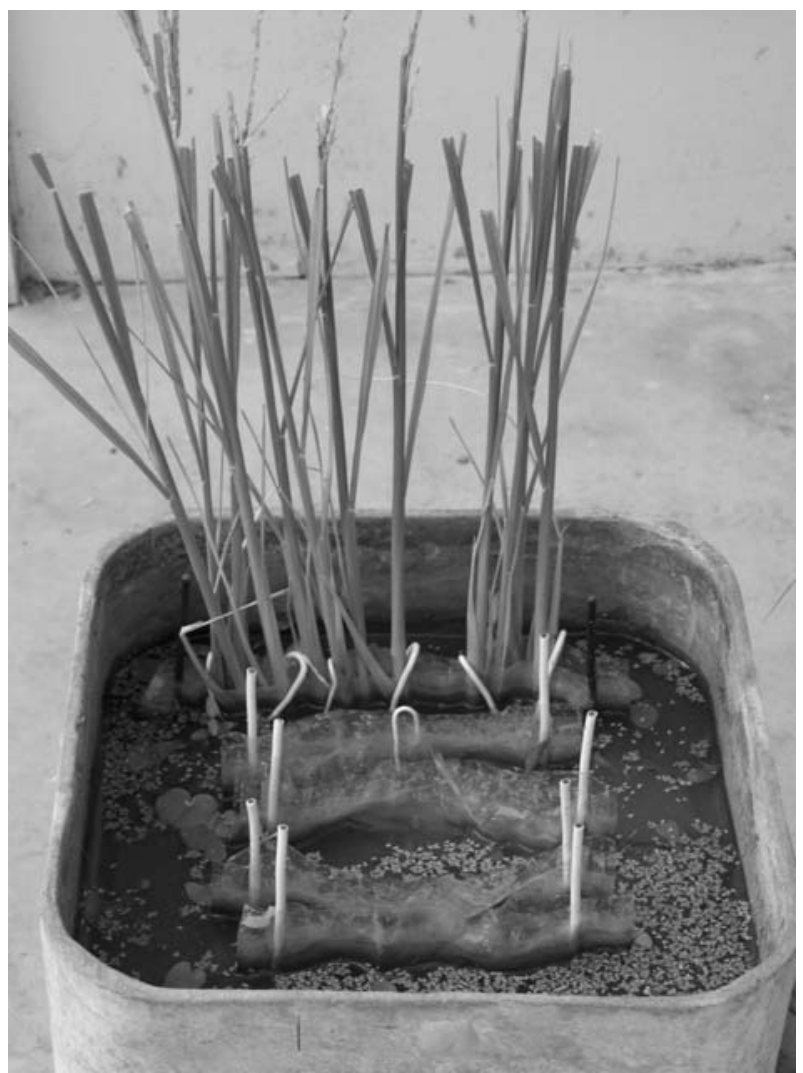

Figura 1. Plantas de arroz alocadas no saco de vinil enterrado no solo alagado.

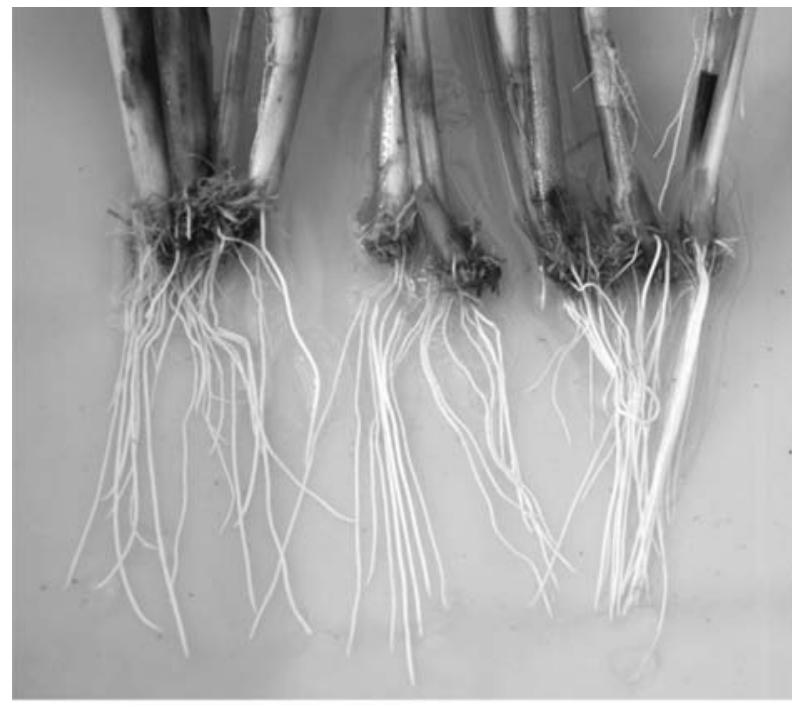

Figura 2. Plantas de arroz retiradas do saco de vinil que foi mantido enterrado no solo alagado.

raízes (limite inferior de detecção do oxímetro utilizado), mostrando a eficiência do método em promover um ambiente de hipoxia.

\section{Placa férrica}

No laboratório, foram cortadas sete raízes de cada genótipo em segmentos de 7,0 cm a partir da ponta. As raízes foram fixadas em um suporte de acrílico, colocadas em uma caixa de vidro $(20 \times 10 \times 1,5 \mathrm{~cm}) \mathrm{e}$ inundadas com $\mathrm{N}$ ultrapuro $\left(<1 \mathrm{mg} \mathrm{L}^{-1} \mathrm{O}_{2}\right)$, visando remover o $\mathrm{O}_{2}$. A caixa de vidro foi preenchida com solução do solo (Planossolo Háplico) (Streck, 2008) previamente alagado, apresentando $\mathrm{pH}=6,2 \mathrm{e}$ $80 \mathrm{mg} \mathrm{L}^{-1}$ de $\mathrm{Fe}\left(\mathrm{Fe}^{2+}\right.$ ) (Figura 3). A solução do solo foi obtida por um sistema composto de um tanque de 50 L, preenchido com um Planossolo Háplico em estádio avançado de redução, conforme Nava (1997). As raízes permaneceram na solução do solo por um período de quatro horas, para que o gradiente de $\mathrm{O}_{2}$ formado entre o interior da raiz (aerênquima) e a solução do solo promovesse a difusão do $\mathrm{O}_{2}$ molecular para o exterior da raiz. Esse tempo de contato foi estabelecido a partir de testes prévios, a fim de evitar que a concentração de Fe na solução caísse para valores muito baixos, dificultando a difusão do Fe para junto das raízes. A liberação do $\mathrm{O}_{2}$ pela raiz e a combinação com o $\mathrm{Fe}^{2+}$ resultam na formação de compostos oxidados de Fe de baixa cristalinidade, formando a placa férrica na superfície da raiz (Figura 3). Posteriormente, as raízes foram lavadas e cortadas em segmentos de 2,0 cm a partir da ponta, compondo as amostras de cada região da raiz, que compreendem os segmentos de 0-2, 2-4 e 4-6 cm. Os segmentos foram fotografados e analisados individualmente. A cada segmento foi adicionado 1,0 $\mathrm{mL}$ de $\mathrm{HCl} \mathrm{0,5} \mathrm{mol} \mathrm{L}^{-1} \mathrm{e}$ mantido em repouso por $24 \mathrm{~h}$ para realizar a extração do Fe contido na raiz, caracterizando cada repetição, num total de sete repetições para cada segmento e genótipo. As concentrações de Fe dissolvido nas amostras foram determinadas por espectrofotômetro de absorção atômica (Nava \& Bohnen, 2002). A partir das imagens digitalizadas, foi calculada a área superficial do segmento com o software SIARCS v. 3.0, que,

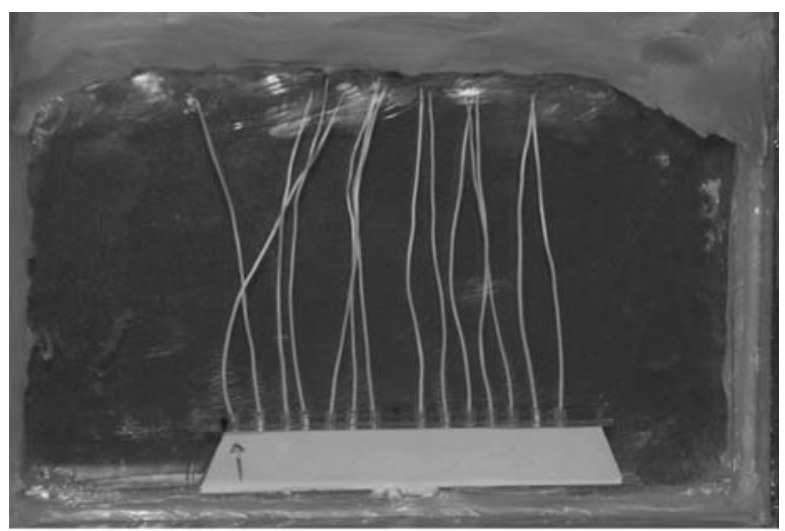

Figura 3. Caixa de vidro com os segmentos de raízes imersas em solução de solo com $\mathrm{pH}=6,2$ e com $80 \mathrm{mg} \mathrm{L}^{-1}$ de Fe. A caixa foi selada com massa de modelar e mantida em ambiente de $\mathrm{N}$ ultrapuro. 
juntamente com a concentração de Fe na amostra, possibilita calcular a distribuição do Fe no segmento.

\section{Porosidade de raízes}

Das plantas usadas para determinação da placa férrica, outro grupo de raízes foi retirado para a determinação da porosidade. Destas, 30 raízes foram cortadas em segmentos de $0-2,2-4$ e $4-6 \mathrm{~cm}$ a partir da ponta, constituindo três repetições para cada segmento e genótipo. Cada unidade experimental constituiu-se de um grupo contendo 10 segmentos. Cada grupo foi cuidadosamente seco com lenço de papel e pesado. Posteriormente, os segmentos foram colocados em uma seringa de plástico de $60 \mathrm{~mL}$ contendo $10 \mathrm{~mL}$ de água. $\mathrm{O}$ volume da seringa foi reduzido para $10 \mathrm{~mL}$, e a entrada dela, vedada com uma tampa de silicone. O êmbolo foi puxado e travado para manter o vácuo por três minutos, a fim de extrair o ar presente na raiz. Após esse tempo, o êmbolo foi solto e mantido por outros três minutos, possibilitando a entrada da água no vácuo criado no interior da raiz. Esse ciclo foi repetido até se observar que todos os segmentos se depositavam no fundo da seringa, indicando que os espaços porosos foram completamente preenchidos com água. As raízes foram retiradas da seringa e novamente secas e pesadas. A diferença de peso antes e depois do tratamento com vácuo e entrada de água foi assumida como sendo a porosidade da raiz, resultando em uma estimativa da magnitude do aerênquima formado em cada segmento ao longo da raiz.

\section{Teste do método}

Foram usados dois genótipos de arroz (IRGA $423 \mathrm{e}$ IRGA 424), cultivados em um Gleissolo háplico (Streck, 2008) até o início do florescimento. As plantas foram retiradas do solo e preparadas como descrito anteriormente. A formação de raízes adventícias foi realizada com 10 plantas em solução nutritiva no saco de vinil no solo alagado e 10 plantas em solução nutritiva com aeração constante $\left(5,0 \mathrm{mg} \mathrm{L}^{-1} \mathrm{de}_{2}\right)$. Após sete dias, foram feitas as determinações da placa férrica e da porosidade.

Para avaliar a eficiência do saco de vinil em evitar a contaminação com $\mathrm{Fe}$, foi feito um branco, com a determinação do $\mathrm{Fe}$ em raízes retiradas do saco de vinil sem a exposição à solução do solo. A concentração de Fe na superfície da raiz, nas duas situações, ficou abaixo dos limites de deteç̧ão do aparelho (dados não apresentados), indicando que não houve contaminação por Fe durante o crescimento das raízes adventícias no saco de vinil mantido enterrado em solo alagado.

Os resultados para porosidade de raiz e placa férrica foram analisados separadamente para cada cultivar testada. O delineamento experimental foi inteiramente casualizado, e os resultados, submetidos à análise de variância a $5 \%$ pelo teste do DMS.

\section{RESULTADOS E DISCUSSÃO}

A porosidade das raízes foi maior quando submetidas ao ambiente sem $\mathrm{O}_{2}$, em relação às plantas cultivadas em solução com aeração nos dois genótipos testados (Figura 4a,b), indicando que o método utilizado para o cultivo de raízes foi eficiente em retirar o $\mathrm{O}_{2}$ e estimular a formação de aerênquima dentro do saco de vinil. A avaliação da porosidade pela determinação em segmentos indica que a formação de aerênquima é maior à medida que aumenta a proximidade com a base da planta (Figura 4a,b), o que está de acordo com Evans (2003), que relata que a indução à formação de aerênquima ocorre a partir das primeiras camadas de células do ápice da raiz e aumenta para a base da planta à medida que a raiz se torna mais madura. Para Gunawardena et al. (2001) e Jackson (1985), a redução da concentração de $\mathrm{O}_{2}$ determina a produção de etileno, sendo este o sinalizador bioquímico para induzir as rotas metabólicas associadas com a morte celular programada e, consequentemente, a formação do aerênquima lisígeno.

A formação de espaços porosos mesmo nas plantas cultivadas com aeração demonstra que há formação de aerênquima mesmo em concentrações de $\mathrm{O}_{2}$ de aproximadamente $5,0 \mathrm{mg} \mathrm{L}^{-1}$ (Figura a,b). No entanto, convém ressaltar que parte dessa porosidade pode ser atribuída aos espaços intercelulares que, de acordo com seu arranjo, formam o aerênquima denominado de constitutivo (Evans, 2003). De acordo com Stolzy (1974), concentrações de $\mathrm{O}_{2}$ inferiores a $12 \%$ no solo alteram negativamente o crescimento e desenvolvimento das raízes de diversas espécies, comprometendo a respiração celular.

As determinações da placa férrica indicam o mesmo comportamento observado para a porosidade entre as condições de oxigenação. À medida que a porosidade aumentou, houve aumento proporcional do Fe oxidado e depositado na superfície das raízes (Figura 4d,c), indicando que oxidação do Fe pode servir como medida em estudos que visem estimar a magnitude da formação de aerênquima da raiz. Essa hipótese é reforçada pela correlação significativa entre a determinação da placa férrica e a da porosidade (Figura 5). A formação da placa férrica foi diferente nos dois genótipos testados; houve diferenças na magnitude do Fe acumulado entre os dois genótipos dentro de cada segmento nas raízes crescidas em hipoxia (Figura 4c,d). Essa variação pode ser atribuída a diferenças na permeabilidade da raiz, o que influencia diferentemente na liberação de $\mathrm{O}_{2}$ para o meio externo. A permeabilidade da raiz é determinada basicamente pela composição química dos tecidos e pelo arranjo das células da epiderme e mesoderme, que são modificadas no decorrer do tempo e aumentam à medida que se aproximam da ponta da raiz (Evans, 2003). 

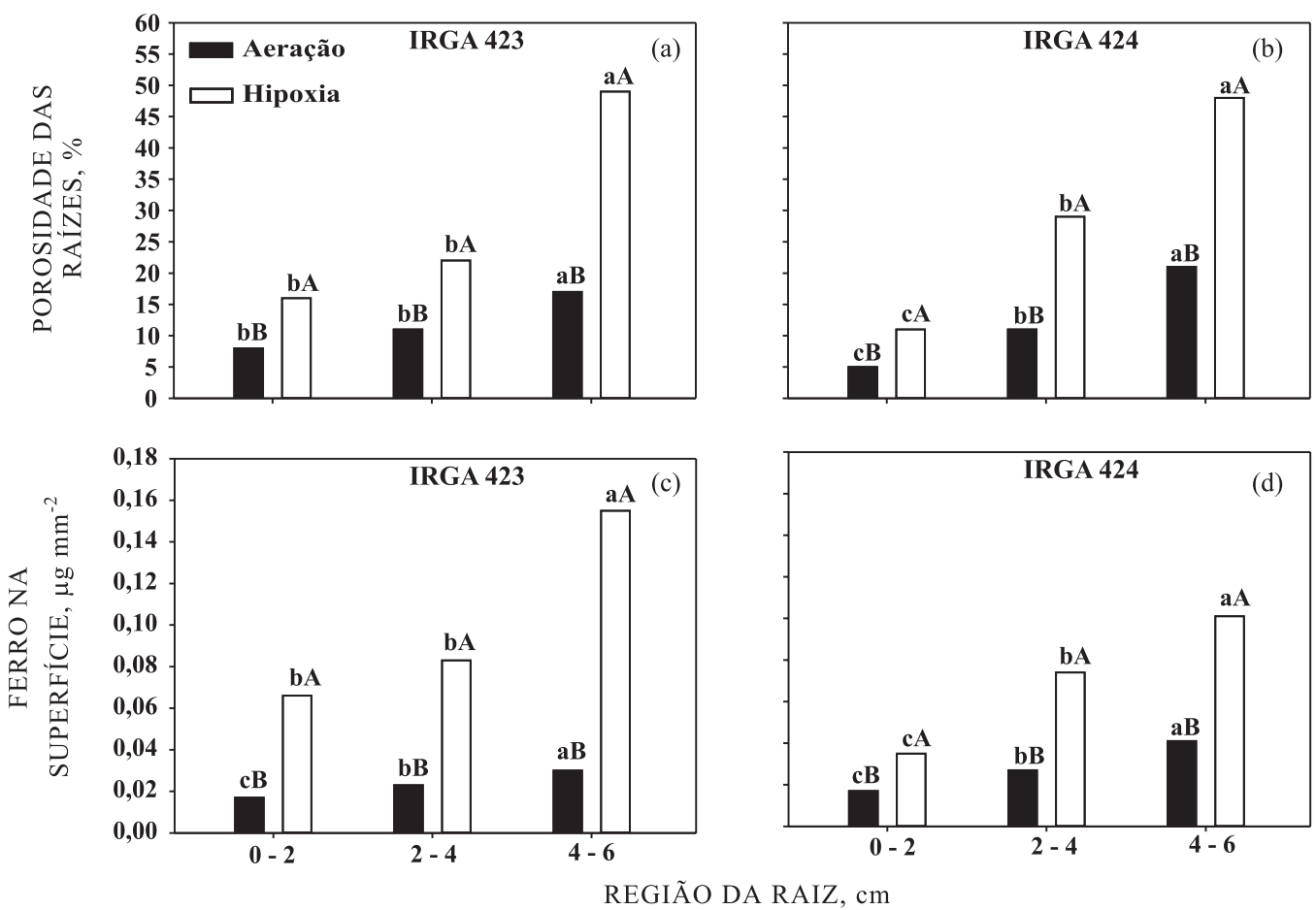

Figura 4. Porosidade e teores de ferro na superfície em segmentos das raízes adventícias em dois genótipos de arroz (IRGA 423 e 424), em função do tratamento das raízes: com ou sem oxigenação (hipoxia). Letras minúsculas comparam as regiões da raiz e letras maiúsculas comparam condições de oxigenação pelo teste do DMS a $5 \%$.

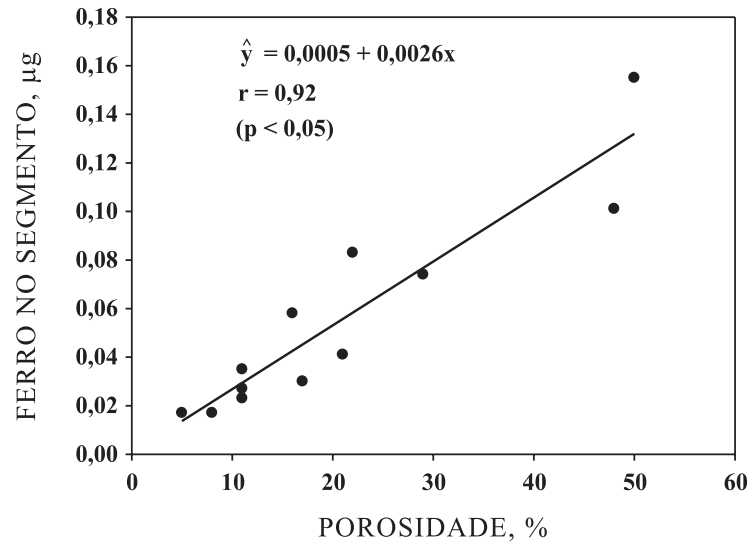

Figura 5. Relação entre a porosidade e a quantidade de ferro em segmentos de raízes adventícias de dois genótipos de arroz (IRGA 423 e 424), mantidos em ambiente com aeração e hipoxia.

\section{CONCLUSÃO}

O método de cultivo de plantas de arroz dentro de sacos de vinil enterrados no solo alagado mostrou-se eficiente em formar um ambiente de hipoxia tal como ocorre em condições normais de cultivo de arroz, permitindo o estudo da formação do aerênquima e placa férrica na raiz em raízes adventícias.

\section{LITERATURA CITADA}

ARMSTRONG, W. Aeration in higher plants. Adv. Bot. Res., 7:225-332, 1979 .

ARMSTRONG, W. Radial oxygen losses from intact rice roots as affected by distance from the apex, respiration, and waterlogging. Physiol. Plant., 25:192-197, 1971.

AULAKH, M.S.; WASSMANN, R.; RENNENBERG, H. \& FINK, S. Pattern and amount of aerenchyma relate to variable methane transport capacity of different rice cultivars. Plant Biol., 2:182-194, 2000.

CHEN, F.R.; SHEN, R.F.; GU, P.; DONG, X.Y.; DU, C.W. \& MA, J.F. Response of rice (Oryza sativa) with root surface iron plaque under aluminum stress. Ann. Bot., 98:389395,2006

CHEN, C.C.; DIXON, J.B. \& TURNER, F.T. Iron coatings on rice roots: Morphology and models of development. Soil Sci. Soc. Am. J., 44:1113-1119, 1980.

CLARK, L.H. \& HARRIS W.H. Observations on the root anatomy of rice (Oryza sativa L.). Am. J. Bot., 68:154$161,1981$.

COLMER, T.D. Long-distance transport of gases in plants: A perspective on internal aeration and radial oxygen loss from roots. Plant Cell Environ., 26:17-36, 2003.

EVANS, D.E. Aerenchyma formation. New Phytol., 161:35$49,2003$. 
GUNAWARDENA, A.; PEARCE, D.M.; JACKSON, M.B.; HAWES, C.R. \& EVANS, D.E. Characterisation of programmed cells death during aerenchyma formation induced by ethylene or hypoxia in roots of maize (Zea mays L.). Planta, 212:205-214, 2001.

GROOT, T.T.; van BODEGOM, P.M.; MEIJER, H.A.J. \& HARREN, F.J.M. Gas transport through the root-shoot transition zone of rice tillers. Plant Soil, 277:107-116, 2005.

HOSONO, T. \& NOUCHI, I. The dependence of methane transport in rice plants on the root zone temperature. Plant Soil, 191:233-240, 1997.

JACKSON, M.B. \& ARMSTRONG, W. Formation of aerenchyma and the processes of plant ventilation in relation to soil flooding and submergence. Plant Biol., 1:274-287, 1999 .

JACKSON, M.B. Ethylene and responses of plants to soil waterlogging and submergence. Ann. Rev. Plant Physiol., 36:145-174. 1985.

JEFFREE, C.E.; DALE, J.E. \& FRY, S.C. The genesis of intercellular spaces in developing leaves of Phaseolus vulgaris L. Protoplasma, 132:90-98, 1986.

JUSTIN, S.H.F.W. \& ARMSTRONG, W. Evidence for the involvement of ethylene in aerenchyma formation in adventitious roots of rice (Oryza sativa L.). New Phytol., 118:49-62, 1991

KLUDZE, H.K.; DELAUNE, R.D. \& PATRICK Jr, W.H Aerenchyma formation and methane and oxygen exchange in rice. Soil Sci. Soc. Am. J., 57:386-391, 1993.
LUXMOORE, R.J.; STOLZY, L. \& LETEY, J. Oxigen diffusion in the soil plant system. Agron. J., 62:317-322, 1970.

NAVA, G. Oxidação do ferro em raízes de duas cultivares de arroz em solução de solo inundado. Porto Alegre, Universidade Federal do Rio Grande do Sul, 1997. 83p. (Tese de Mestrado)

NAVA, G. \& BOHNEN, H. Oxidação de ferro de dois cultivares de arroz em solução de solo inundado. R. Bras. Ci. Solo, 26:325-332, 2002

PONNAMPERUMA, F.N. The chemistry of submerged soils. Adv. Agron., 24:29-96, 1972.

SILVA, L.S. \& BOHNEN, H. Rendimento e acúmulo de nutrientes pelo arroz em solução nutritiva com e sem adição de silício. R. Bras. Ci. Solo, 25:771-777, 2001.

STRECK, E.V.; KÄMPF, N.; DALMOLIN, R.S.D.; KLAMT, E.; NASCIMENTO, P.C.; SCHNEIDER, P.; GIASSON, E. \& PINTO, L.F.S. Solos do Rio Grande do Sul. 2.ed. Porto Alegre, EMATER/RS, 2008. 222p.

STOLZY, L.H. Soil atmosphere. In: CARSON, E.W., ed. The plant root and its environment. Charlottesville, University of Virginia, 1974. p.335-355.

TANAKA, A. \& NAVASERO, S.A. Growth of the rice plant on acid sulfate soils. Soil Sci. Plant Nutr., 12:107-114, 1966.

THOMSON, C.J.; ARMSTRONG, W.; WATERS, I. \& GREENWAY, H. Aerenchyma formation and associated oxygen movement in seminal and nodal roots of wheat. Plant Cell Environ. 13:395-403, 1990. 